\title{
Tephra hazard assessment at Mt. Etna (Italy)
}

\author{
S. Scollo ${ }^{1}$, M. Coltelli ${ }^{1}$, C. Bonadonna ${ }^{2}$, and P. Del Carlo ${ }^{3}$ \\ ${ }^{1}$ Istituto Nazionale di Geofisica e Vulcanologia, Osservatorio Etneo, Sezione di Catania, Catania, Italy \\ ${ }^{2}$ Section des sciences de la Terre et de l'environnement, Université de Genève, Geneva, Switzerland \\ ${ }^{3}$ Istituto Nazionale di Geofisica e Vulcanologia, Sezione di Pisa, Pisa, Italy \\ Correspondence to: S. Scollo (simona.scollo@ct.ingv.it)
}

Received: 1 March 2013 - Published in Nat. Hazards Earth Syst. Sci. Discuss.: 28 June 2013

Revised: 7 November 2013 - Accepted: 8 November 2013 - Published: 12 December 2013

\begin{abstract}
In this paper we present a probabilistic hazard assessment for tephra fallout at Mt. Etna (Italy) associated with both short- and long-lived eruptions. Eruptive scenarios and eruption source parameters were defined based on the geological record, while an advection-diffusion-sedimentation model was used to capture the variation in wind speed and direction with time after calibration with the field data. Two different types of eruptions were considered in our analysis: eruptions associated with strong short-lived plumes and eruptions associated with weak long-lived plumes. Our probabilistic approach was based on one eruption scenario for both types and on an eruption range scenario for eruptions producing weak long-lived plumes. Due to the prevailing wind direction, the eastern flanks are the most affected by tephra deposition, with the 122 BC Plinian and 2002-2003 eruptions showing the highest impact both on infrastructures and agriculture.
\end{abstract}

\section{Introduction}

Volcanic eruptions close to inhabited areas represent a major natural hazard that includes lava flows, tephra fallout, mudflows, toxic gases and other phenomena that can be triggered during volcanic activity (e.g. tsunamis, deformation, floods, tremors). Social and economic disruptions increase in relation to population growth (Tilling and Lipmann, 1993) and depend on the size and type of the eruption, on the prevailing wind direction and on the distance to the volcanic vent. In order to reduce the risk associated with volcanic activity, careful land-use planning requires a reliable evaluation of the hazard associated with different eruptive phenomena. Among these, tephra fallout can cause collapse of buildings and damage to both agriculture and transportation networks (Blong, 1984; Sparks et al., 1997). In addition, fine ash can be associated with long-term health effects such as silicosis and chronic pulmonary diseases (Horwell and Baxter, 2006), and when injected into the atmosphere it can be extremely dangerous for air traffic. In fact, fine ash can cause severe damage to aircraft jet engines due to both the accumulation of melted glass particles and erosion of turbine blades, interfere with electronic equipment, obstruct the Pitot tubes that measure air speed, obscure the windscreen and landing lights and other damaging effects (Casadevall, 1994; Miller and Casadevall, 2000).

Recent studies of hazard assessment from tephra fallout have highlighted the need to combine field data of past eruptions with probabilistic approaches using well-calibrated models (e.g. Barberi et al., 1990; Cioni et al., 2003; Hurst and Smith, 2004; Bonadonna et al., 2005a, b; Magill et al., 2006). While the knowledge of stratigraphic records allows for the characterization of the eruptive activity of a given volcano and for the evaluation of the recurrence time, models of tephra dispersal help quantify the potential impact of a specific phenomenon. Cioni et al. (2003) showed how probabilistic assessments represent a significant improvement to the hazard evaluation for different volcanic phenomena and volcanic vents with respect to deterministic approaches. However, models need to be calibrated with reliable data sets.

Although high-intensity explosive activity is rare at Mt. Etna, eruptions ranging from violent strombolian to subplinian frequently occur from the summit craters, and fissures can open on volcano flanks. Usually, violent strombolian activity produces weak plumes that last from hours to months and affect the lower troposphere, whereas the paroxysmal phase of subplinian eruptions lasts from a few minutes 
to hours and may reach the tropopause. As an example, between November 2002 and January 2003 a volcanic plume produced by the eruptive fracture opened on the upper SE flank of Etna at $2750 \mathrm{~m}$ above sea level (a.s.l.) and formed copious tephra fallout in the eastern part of Sicily (Andronico et al., 2005, 2008). During this eruption about $80 \%$ of crops were damaged, houses suffered structural damage and transport operations were heavily affected. Roads were covered by ash and the reduced visibility and the slipperiness caused several accidents (Barnard, 2004). Furthermore, the airports of Catania and Reggio Calabria were forced to close for several weeks (Andronico et al., 2005). Recently, Etna was very active, producing 39 lava fountain events between 12 January 2011 and 26 October 2013. During the paroxysmal phases that lasted on average about one hour, the eruptive column rose up to about $11 \mathrm{~km}$ a.s.l. (e.g. 8 September 2011). Most of those events formed copious tephra fallout mainly in the eastern sector and forced the closure of the international airport of Catania. A detailed quantification of the impact associated with tephra fallout is necessary even for basaltic volcanoes such as Etna, which are typically considered as mostly characterized by effusive activity.

The reconstruction of the geological records for basaltic volcanoes is not an easy task. Thin tephra deposits are usually not preserved, because they are eroded away soon after the eruptive event (hours or days). Violent strombolian activity can last several days (e.g. 2001 and 2002-2003) and its characterization is often difficult due to the high variability of eruptive phenomena and meteorological conditions that influence and scatter the fallout sedimentation (Andronico et al., 2008; Scollo et al., 2007). However, constant monitoring of the explosive activity at Etna has been performed during the last two decades (Alparone et al., 2007; Scollo et al., 2009; Andronico et al., 2009). An exceptional amount of data was collected thanks to many field surveys that were carried out at the end of explosive activities (e.g. the 2001 Etna eruption, Scollo et al., 2007; the 1998 Etna eruption, Andronico et al., 1999; the 1990 Etna eruption, unpublished data; 122 BC, Coltelli et al., 1998).

We considered two categories of explosive eruptions at Mt. Etna, the first producing strong short-lived plumes (SSL eruptions) and the second producing weak long-lived plumes (WLL eruptions, also named Class B eruptions by Branca and Del Carlo, 2005). Eruption source parameters were identified for each category (column height, total mass, total grain-size distribution, density of the deposit). Information was also obtained by direct observations of volcanologists working at the former CNR Istituto Internazionale di Vulcanologia and, since 2001, at the Istituto Nazionale of Geofisica e Vulcanologia, sezione di Catania. In addition, we have considered the record of explosive eruptions identified within the Holocene tephrostratigraphic succession of Etna (Del Carlo et al., 2004) and the historical reports of the post1669 AD period (Branca and Del Carlo, 2005) to include information concerning the volcanological features of Etna explosive activity. The hazard has been evaluated quantitatively using the TEPHRA model (Bonadonna et al., 2005a) already used to study some Etna eruptions (Scollo et al., 2008a). The model was configured to include the time factor necessary for modelling WLL eruptions. Probabilistic maps for both SSL and WLL eruptions were hence performed after model calibration for both typologies.

\section{Etna explosive activity}

The current Etna activity is produced by the Mongibello volcanic center from its summit craters or lateral vents opened on volcano flanks down to a few hundred metres in altitude. Eruptions from the summit craters and/or branches of the central conduits are more common than flank eruptions fed by independent paths (Rittmann, 1973). Although a wide variety of explosive activity does indeed take place, for many years this has been considered subordinate compared to the frequent lava flow eruptions for which Etna is generally known. The thick volcaniclastic successions that blanket the eastern slope of the Etna edifice testified to important explosive activity in Late Pleistocene and Holocene times. For the last $12 \mathrm{ka}$ at least 25 subplinian (Branca and Del Carlo, 2005) and one Plinian (in 122 BC; Coltelli et al., 1998) eruptions have occurred at Etna. After the 1669 eruption, the largest and most destructive historical eruption whose eruptive vents opened at low altitude on the SE flank of the volcano (about $900 \mathrm{~m}$ a.s.l.), the method of observing and describing the eruptive events changed toward a more modern conception with more detailed reports. The critical review of the historical reports over the last four centuries carried out by Branca and Del Carlo (2005) showed that subplinian eruptions (SSL) at Mt. Etna were produced by summit craters and lasted from a few minutes to hours, generally during periods of longlived strombolian activity at the summit craters; nonetheless, on a few occasions (e.g. 17 July 1960) they occurred during periods of quiescence. Since 1670, at least 12 subplinian eruptions have taken place (see Table 1 in Branca and Del Carlo, 2005). These events produced several kilometre-high eruptive columns that caused tephra fallout over very wide areas to distances of hundreds of kilometres. On the contrary, long-lived explosive activity has usually been produced by vents opened mainly on the SE flank (WLL eruptions). This type of eruption produces weak eruptive plumes and proximal deposits that form large scoria cones or coalescent cones (see Table 2 in Branca and Del Carlo, 2005). Since 1990, Etna has produced a very large number (more than 150) of violent explosive events with fire fountains that formed eruptive columns from 5 to $15 \mathrm{~km}$ a.s.l. and erupted tephra volume from $10^{4}$ to $10^{7} \mathrm{~m}^{3}$ (Branca and Del Carlo, 2005). These eruptions have been thoroughly described for tephra fallout dispersion and eruptive parameters (e.g. Andronico et al., 2008). 
Table 1. Eruption source parameters used in the hazard assessment: $M$ is the total mass, $H$ the column height and $M d_{\varphi}$ and $\sigma_{\varphi}$ are mode and standard deviation of the TGSD.

\begin{tabular}{lrrrr}
\hline & $M(\mathrm{~kg})$ & $H(\mathrm{~km})$ & $M d_{\varphi}$ & $\sigma_{\varphi}$ \\
\hline SSL-Calibration 1998 eruption & $1.3 \times 10^{9}$ & 12 & 2.3 & 1.5 \\
WLL-Calibration 2001 eruption & $2.3 \times 10^{9}$ & $3.5-5.5$ & 2 & 1.5 \\
OES-SSL1 1990 eruption & $1.5 \times 10^{10}$ & 15 & -0.5 & 1.5 \\
OES-SSL2 122 BC eruption & $2.8 \times 10^{11}$ & $24-26$ & 2.3 & 1.5 \\
OES-WLL 2002-2003 eruption & $4.4 \times 10^{10}$ & 7 & 0.5 & 1.5 \\
ERS-WLL & $1.5 \times 10^{6}-5 \times 10^{9}$ & $3.6-7$ & $-0.5-2.3$ & 1.5 \\
\hline
\end{tabular}

\section{Modelling}

Hazard assessment from tephra fallout is quantified using a 2-D advection-diffusion model named TEPHRA, which semi-analytically solves the mass conservation equation (see Bonadonna et al., 2005a for the model description). TEPHRA includes the grain size-dependent diffusion law (Suzuki, 1983), particle density variation (Bonadonna and Phillips, 2003), stratified atmosphere (Bonadonna et al., 2002; Connor et al., 2001; Macedonio et al., 1988) and terminal settling velocity as a function of the particle Reynolds number (Bonadonna et al., 1998). TEPHRA uses parallel techniques (it is written in ANSI C and uses the MPI library) suitable for the application of probabilistic approaches that require many simulations and hence are highly timeconsuming. Input parameters of TEPHRA are:

- Plume height $(H)$ : maximum height of the eruptive column determined from ground observations (e.g. Andronico et al., 2008), from satellite retrievals (e.g. Prata and Grant, 2001) and/or analysis of the field deposit (e.g. Carey and Sparks, 1986).

- Total mass $(M)$ : total erupted mass extrapolated from the deposit (e.g. Bonadonna and Houghton, 2005), from statistical analysis (Scollo et al., 2008a) or extracted from empirical laws correlating the total mass with the column height (e.g. Sparks et al., 1997).

- Total grain-size distribution (TGSD): total grain-size distribution modelled as a Gaussian distribution having a mode $M d_{\varphi}$ and standard deviation $\sigma_{\varphi}$. It can be extrapolated from the tephra deposit by using different methodologies (see Bonadonna and Houghton, 2005 for a review) or estimated with a theoretical model of tephra dispersal (Mannen, 2006).

- Density of lithics and pumices (DL, DP): density of particles usually measured in the laboratory (e.g. Houghton and Wilson, 1989; Eychenne and Le Pennec, 2012) or using simple parameterizations (Bonadonna and Phillips, 2003).
In addition, three empirical parameters need to be evaluated through model calibration (e.g. Bonadonna et al., 2002; Scollo et al., 2007):

- Horizontal diffusion coefficient $(K)$. This parameter accounts for atmospheric diffusion and horizontal gravitational spreading of volcanic clouds. If the particle fall time is small, the diffusion can be described by Fick's law and the variance $\sigma_{i j}^{2}$ :

$\sigma_{i j}^{2}=4 K\left(t_{i j}+t_{i}^{\prime}\right)$,

where $i$ indicates the point sources along the eruptive plume, $j$ is the particle size, $K\left(\mathrm{~m}^{2} \mathrm{~s}^{-1}\right)$ is the atmospheric horizontal diffusion coefficient, $t_{i j}(\mathrm{~s})$ is the fall time of a particle of size $j$ released from a point source $i$ along the eruptive plume, and $t_{i}^{\prime}(\mathrm{s})$ is the horizontal diffusion time in the vertical plume, which accounts for the change in width of the vertical plume with height (Ernst et al., 1996; Woods, 1995; Morton et al., 1956; Sparks and Wilson, 1982; Bonadonna et al., 2005a). For particle fall times with a scale of hours, the diffusion is described by a power law (Suzuki, 1983):

$\sigma_{i j}^{2}=\frac{8 C}{5}\left(t_{i j}+t_{i}^{\prime}\right)^{2.5}$,

where $C$ is the apparent eddy diffusivity determined empirically with $C=0.04 \mathrm{~m}^{2} \mathrm{~s}^{-5 / 2}$ (Suzuki, 1983).

- Fall-time threshold (FTT): parameter that indicates the shift between Fickian and power-law diffusion. Large values of FTT mean that a large number of particle sizes follow the linear diffusion, and therefore produce a thick and narrow deposit in the proximal area centered along the dispersal axis.

- Plume ratio (PR): parameter related to the plume mass distribution. The mass of erupted tephra is assumed to be uniformly distributed with height, but there is the option of choosing where the mass is located (i.e. the ratio between total height and the lower plume level where particles start being released). 


\subsection{Model configuration}

Semi-analytical tephra dispersal models assume that volcanic particles are instantaneously released at time zero (e.g. TEPHRA, Bonadonna et al., 2005a; HAZMAP, Barberi et al., 1990; Macedonio et al., 2005; ASHFALL, Hurst and Turner, 1999). They are usually applied to relatively short-lived activity, such as subplinian and Plinian eruptions (Suzuki, 1983; Armienti et al., 1988; Hurst and Turner, 1999; Connor et al., 2001). Nevertheless, violent strombolian eruptions, such as the 2001 and 2002-2003 Etna eruptions, can last several days (Scollo et al., 2007; Andronico et al., 2008) and are significantly affected by wind variations (Bursik et al., 1992; Sparks et al., 1997). TEPHRA was hence modified to account for the variation in wind direction and speed with time in order to compile a comprehensive hazard assessment of WLL eruptions. In particular, a specific number of wind profiles, $n$, associated with a given eruption is determined by dividing the total eruption duration by the interval between available wind profiles (e.g. six hours for the atmospheric sounding data of the Italian Air Force (IAF) at Trapani Birgi, located in western Sicily and available at http://weather.uwyo.edu). For instance, if the total eruption duration is $84 \mathrm{~h}$, the number of wind profiles $n$ is 14 . When the duration cannot be precisely divided by the time interval $(6 \mathrm{~h})$, the number of wind profiles is approximated. The total erupted mass is then divided by $n$, and $n$ eruptions of a mass of $M / n$ are sequentially run assuming constant eruptive parameters (i.e. $H$, TGSD, DL and DP, PR, $K$, FTT). The fraction $m_{i, j}$ of particles with size $j$ that fall from a point source $i$ to a point on the ground with coordinates $(x, y)$ is determined as the sum of the contribution of the $n$ eruptions of mass $M / n$ :

$m_{i, j}(x, y)=\sum_{s=1}^{n} m_{i, j}(x, y)$,

where $s$ indicates the simulations between 1 and $n$.

\section{Model calibration}

TEPHRA is calibrated by varying empirical parameters $(K$, FTT and PR) and finding the best fit between computed and observed data by the minimum of the $m f$ function (Bonadonna et al., 2002):

$m f=\sqrt{\frac{\sum_{N}\left(M_{\mathrm{obs}}-M_{\mathrm{comp}}\right)^{2}}{N-1},}$

where $N$ is the number of the field data, and $M_{\mathrm{obs}}\left(\mathrm{kg} \mathrm{m}^{-2}\right)$ and $M_{\text {comp }}\left(\mathrm{kg} \mathrm{m}^{-2}\right)$ are the observed and computed masses accumulated per area unit. The calibration was carried out for SSL and WLL eruptions. The SSL calibration is based on the 22 July 1998 eruption (Aloisi et al., 2002; Andronico et al., 1999; Scollo et al., 2008a) and the WLL calibration on the
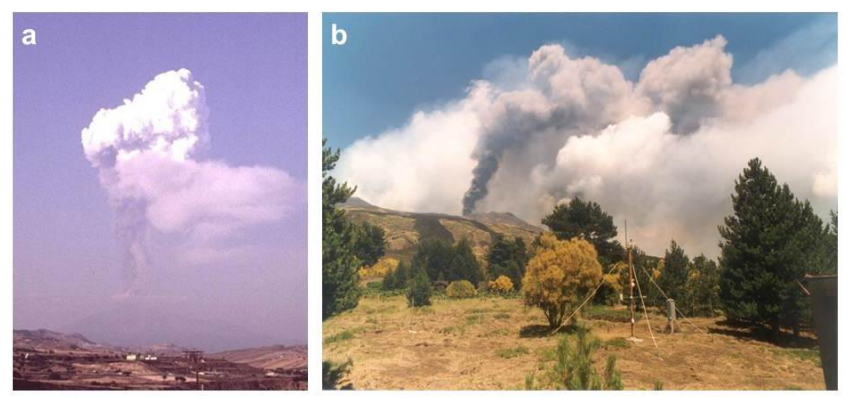

Fig. 1. Examples of (a) SSL plume produced during the 22 July 1998 Etna eruption (courtesy of M. Pompilio); (b) WLL plume formed on 24 July 2001 (photo taken by S. Scollo).

21-24 July phase of the 2001 eruption (Scollo et al., 2007). These two eruptions were chosen as case studies due to the associated large data sets.

\subsection{Model calibration for eruptions generating strong short-lived plumes}

Calibration of the SSL eruptions was based on data collected after the activity of 22 July 1998, one of the largest and most studied events occurred at Etna since the last century (Andronico et al., 1999; Scollo et al., 2008a; Bonadonna and Costa, 2013). A sustained column reached an altitude of $12 \mathrm{~km}$ (a.s.l.), forming a typical strong plume (Fig. 1a). The wind direction was almost constant, about $140^{\circ}$ from the north, up to $10 \mathrm{~km}$ a.s.l. where it rotated toward NE (about $50^{\circ}$ from the north) and with an intensity of less than $10 \mathrm{~m} \mathrm{~s}^{-1}$ (Aloisi et al., 2002). The eruption produced an abundant tephra fallout deposit on the southeastern flank. Thirty-five samples were collected a few hours after the end of the eruptive episode; from the analysis of the tephra deposit, the eruption was classified as subplinian (Andronico et al., 1999). The total mass of pyroclastic material erupted was estimated using Pyle's method (1989) at about $1.3 \times 10^{9} \mathrm{~kg}$ (Andronico et al., 1999), and the total grain-size distribution was centered on $2.3 \varphi$ with a standard deviation of 1.5 (Scollo et al., 2008a) using Voronoi's method (Bonadonna and Houghton, 2005). Model calibration was carried out varying $K$ between 0.001 and $6800 \mathrm{~m}^{2} \mathrm{~s}^{-1}$, FTT between 36 and $3600 \mathrm{~s}$ and PR between 0 and 1 . The best-fit values were obtained for $K$ equal to $200 \mathrm{~m}^{2} \mathrm{~s}^{-1}$, FTT equal to $180 \mathrm{~s}$ (i.e. $0.05 \mathrm{~h}$ ) and PR equal to 0.4 (Fig. 2a, b and c). On the basis of these values, a new simulation was performed and local differences among the computed best-fit values and the field data were evaluated at each sample point (Fig. 2d). The largest discrepancies are shown by locations with mass accumulation $>10 \mathrm{~kg} \mathrm{~m}^{-2}$. Finally, the comparisons among the grain-size distributions of the samples and those computed at the same locations show a good agreement at different distances from the vent (Fig. 3). 

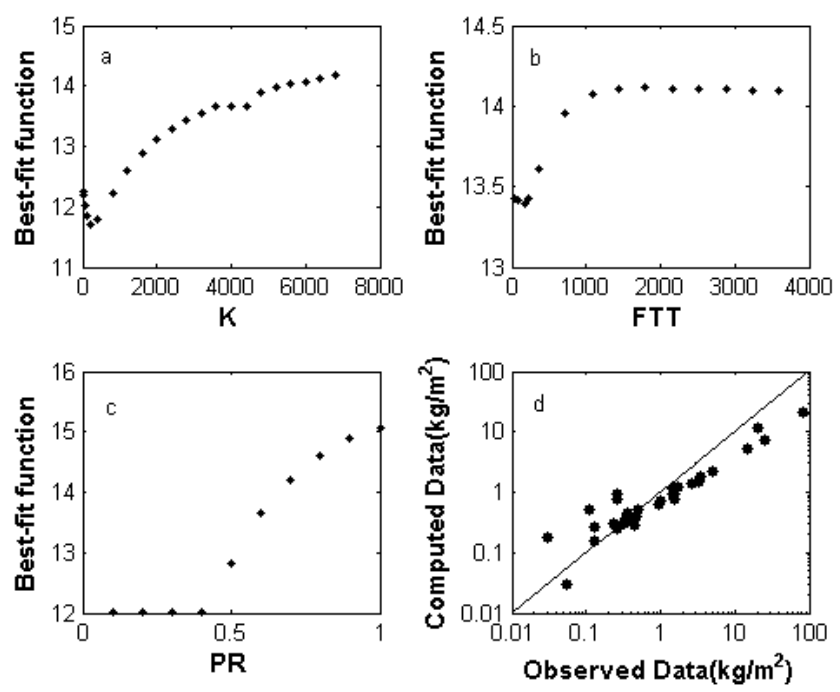

Fig. 2. Misfit function calculated varying: (a) the atmospheric horizontal diffusion coefficient $(K)$ between 0.001 and $6800{ }^{2} \mathrm{~s}^{-1}$; (b) the fall-time threshold (FTT) between 36 and $3600 \mathrm{~s}$ and (c) the plume ratio (PR) between 0 and 1; (d) Log plot shows the comparison between computed and observed data. Computed data are obtained by introducing the following best-fit values into the model: $K=200 \mathrm{~m}^{2} \mathrm{~s}^{-1}, \mathrm{FTT}=180 \mathrm{~s}$, and PR $=0.4$.
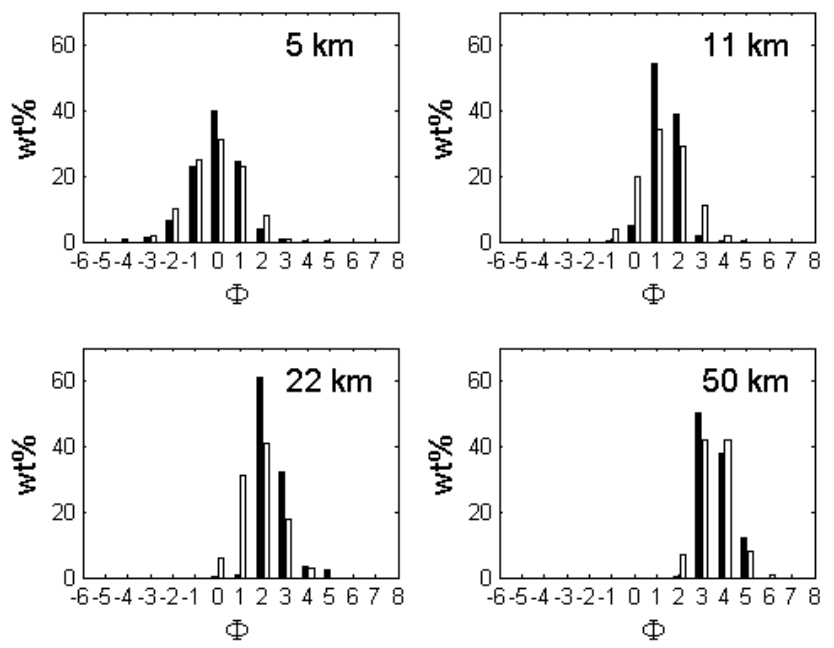

Fig. 3. Comparison between observed grain-size distribution of the tephra deposit (black) associated with the 22 July 1998 eruption of Etna (Andronico et al., 1999) and grain-size distribution (grey) computed at the same locations, Rifugio Sapienza, Tardaria, Sant'Agata Li Battiati and Agnone, respectively 5, 11, 22, and $50 \mathrm{~km}$ from the volcanic vent.

\subsection{Model calibration for eruptions generating weak long-lived plumes}

The WLL calibration was based on data collected after the first phreatomagmatic phase of the 2001 Etna eruption
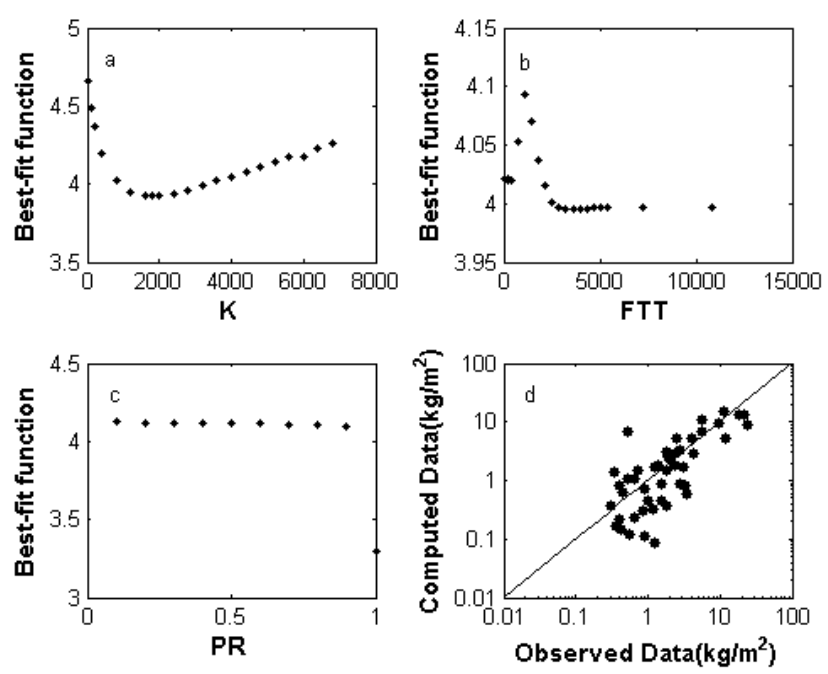

Fig. 4. Misfit function calculated varying the atmospheric horizontal diffusion coefficient $(K)$ between 0.001 and $6800 \mathrm{~m}^{2} \mathrm{~s}^{-1}$, the fall-time threshold (FTT) between 36 and $10800 \mathrm{~s}$, and PR between 0 and 1 . Log plot shows the comparison between computed and observed data with the best-fit values obtained from the results of the sensitivity test for $K=1800 \mathrm{~m}^{2} \mathrm{~s}^{-1}$, FTT $=2520$ s (i.e. $0.7 \mathrm{~h}$ ) and $\mathrm{PR}=1$.

between 21 and 24 July (Fig. 1b), already used for validating several models (Scollo et al., 2007; Costa et al., 2006; Barsotti et al., 2008). During this event, a weak and longlived plume that rose up to about $5 \mathrm{~km}$ in altitude opened at $2570 \mathrm{~m}$ a.s.l. on the SE flank of Etna. The deposit was bilobate in shape due to the change in explosive intensity, wind direction and velocity. It covered the area between Giarre and Catania, with two dispersal axes toward S and SSE. From the analysis of 46 samples, a total volume of $2.32 \times 10^{9} \mathrm{~kg}$ and a total grain-size distribution peaked at $2 \varphi$ were calculated by using the power law and Voronoi's methods, respectively (Scollo et al., 2007).

Like the SSL eruption calibration, $K$ varied between 0.001 and $6800 \mathrm{~m}^{2} \mathrm{~s}^{-1}$, FTT between 36 and $10800 \mathrm{~s}$, and PR between 0 and 1 (Fig. 4a, b and c). Best-fit values were obtained for $K$ equal to $1800 \mathrm{~m}^{2} \mathrm{~s}^{-1}$, FTT equal to 2520 s (i.e. $0.7 \mathrm{~h}$ ), and PR equal to 1 . The agreement between computed and field data is shown in Fig. 4d, while the comparison between grain-size distributions of the collected samples and grainsize distributions computed at the same locations is shown in Fig. 5.

\section{Wind data analysis}

We analysed wind data from atmospheric soundings by the IAF from January 1990 to 2003 (data available at http://weather.uwyo.edu). Comparisons carried out between data obtained by radio-sounding balloons in Trapani and radio-sounding balloons launched in the proximity of 

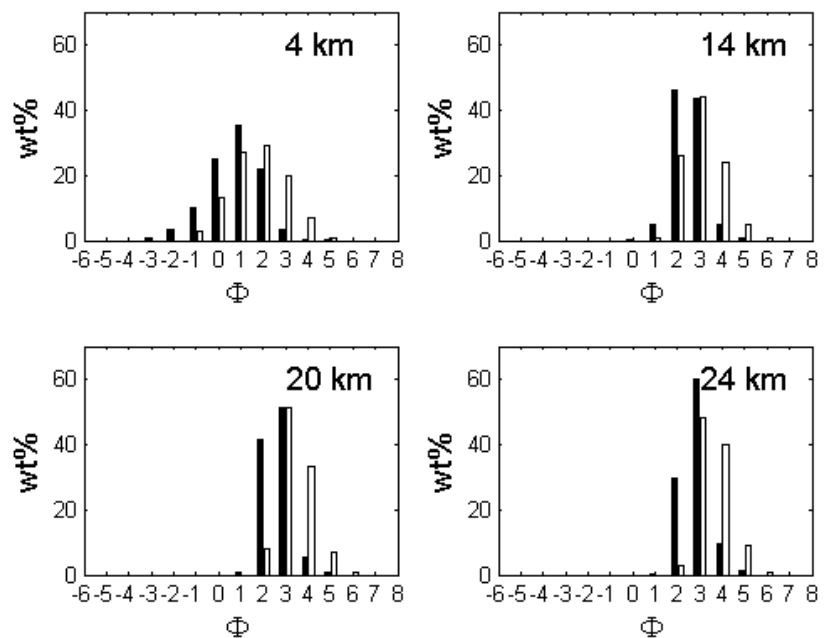

Fig. 5. Comparisons between the observed grain-size distribution of the tephra deposit (black) associated with the 21-24 July eruption of Etna and grain-size distribution (grey) computed at the same location. Field data were collected respectively at about 4, 14, 20, and $24 \mathrm{~km}$ from the volcanic vent.

Etna (Coltelli et al., 2011, INGV technical report available at http://istituto.ingv.it/l-ingv/produzione-scientifica/ rapporti-tecnici-ingv/rapporti-tecnici-2011) have shown that tropospheric differences are $<35^{\circ}$ with a mean value of $15^{\circ}$ for the wind direction, and $<10 \mathrm{~m} \mathrm{~s}^{-1}$ with a mean value of $4 \mathrm{~m} \mathrm{~s}^{-1}$ for the wind speed. As a result, we consider this data set reliable for the compilation of hazard assessments of tropospheric eruptions at Mt. Etna.

Data were converted to a compatible format for the TEPHRA model that requires the direction (degree calculated from the north of provenance $+180^{\circ}$ ) and wind speed $\left(\mathrm{m} \mathrm{s}^{-1}\right)$ from 1 to $30 \mathrm{~km}$ in altitude, in $1 \mathrm{~km}$ steps. Winds usually blow to the southeast in the lower troposphere, moving toward the east as altitude increases (Fig. 6a). The mean direction of the wind is between $97^{\circ}$ and $173^{\circ}$ (provenance of the wind $+180^{\circ}$ ) with a standard deviation between $38^{\circ}$ and $93^{\circ}$. The mean speed is roughly between 7 and $23 \mathrm{~m} \mathrm{~s}^{-1}$ with a standard deviation between 4 and $11 \mathrm{~m} \mathrm{~s}^{-1}$ (Fig. 6b). The wind speed increases regularly in the troposphere up to $11 \mathrm{~km}$ in altitude (going up to $25 \mathrm{~m} \mathrm{~s}^{-1}$ ) and decreases at the tropopause, dropping regularly to $8.5 \mathrm{~m} \mathrm{~s}^{-1}$ at $20 \mathrm{~km}$ in altitude (Fig. 6b). Plotting wind directions for different altitudes $(5,10,15$ and $20 \mathrm{~km})$ in Fig. 7 , we may evaluate its maximum probability that is mainly between $90^{\circ}$ and $120^{\circ}$.

\section{Hazard assessment}

In our analysis we have compiled probability maps for:

- One eruption scenario of SSL eruption based on two large explosive events of Mt. Etna: (i) the 1990 eruption, the largest eruptive event in the last three
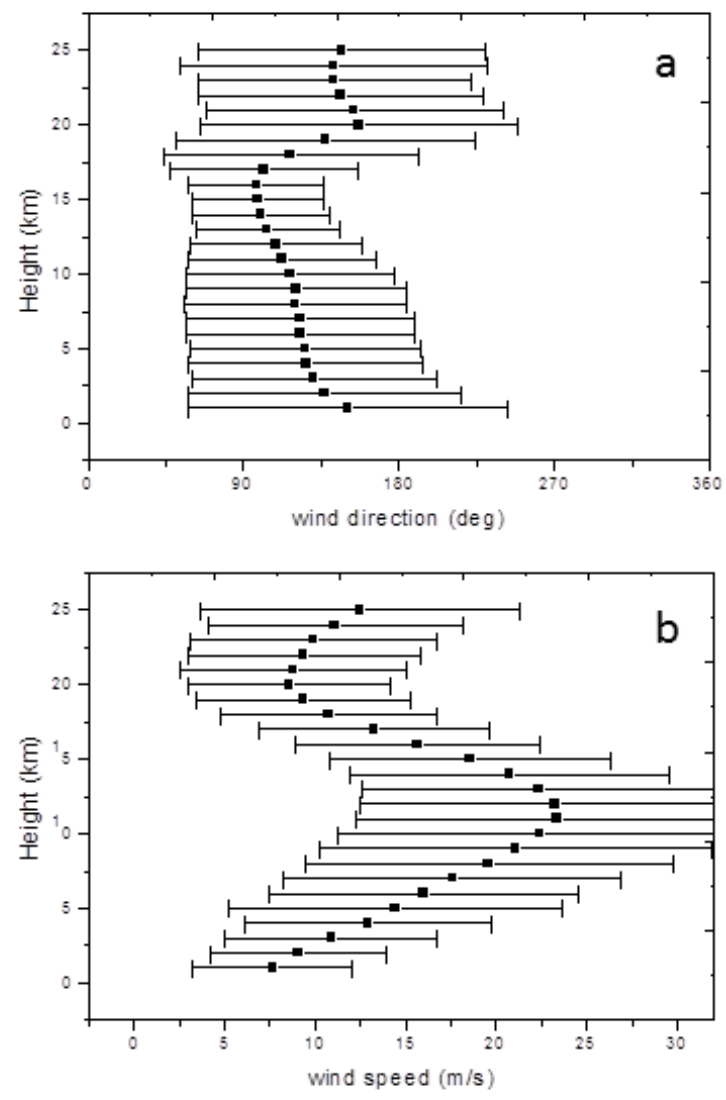

Fig. 6. Plots showing: (a) the mean wind direction (provenance $+180^{\circ}$ ) and (b) the mean wind speed every $\mathrm{km}$ over $15 \mathrm{yr}$ of wind profiles sampled 4 times a day (00:00; 06:00, 12:00, 18:00 LT) from 1 January 1990 up to 2003. The standard deviation for each height level is also reported. Data are available at http://weather.uwyo.edu.

centuries; category 1 (OES-SSL1) and (ii) the Plinian eruption of $122 \mathrm{BC}$, the largest eruptive event occurring in the last $12000 \mathrm{yr}$; category 2 (OES-SSL2).

- One eruption scenario of WLL eruption (OES-WLL) based on the 2002-2003 eruption.

- Eruption range scenarios of WLL eruption (ERSWLL) based on WLL eruptions recorded in the last three centuries.

OES and ERS are described in Bonadonna (2006). We also considered the following hazardous thresholds: (i) roof collapse (100, 200 and $300 \mathrm{~kg} \mathrm{~m}^{-2}$; Cioni et al., 2003) and (ii) damage to vegetation $\left(10 \mathrm{~kg} \mathrm{~m}^{-2}\right.$; Bonadonna et al., 2005a). The main eruption source parameters used in our analysis are reported in Table 1. 

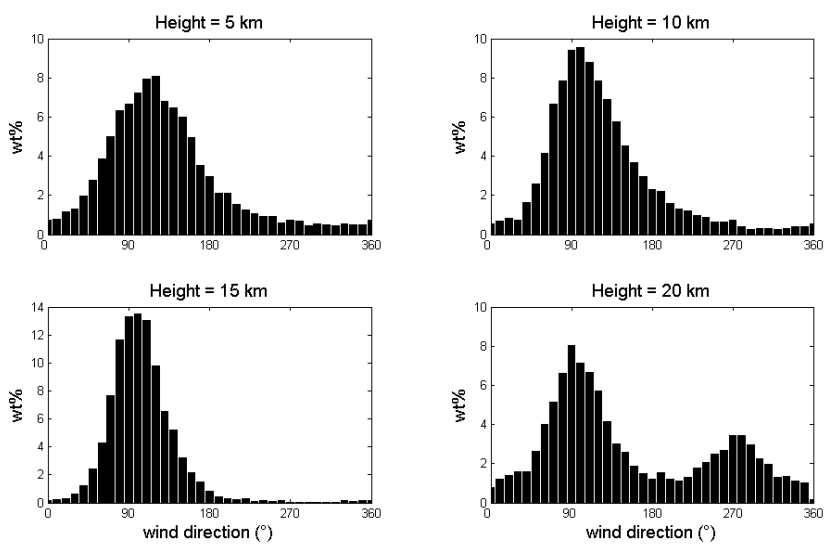

Fig. 7. Plots showing the percentage of wind direction between $0^{\circ}$ and $360^{\circ}$ (from the north) at four different altitude levels (i.e. 5, 10, 15 and $20 \mathrm{~km}$ ). Data are available at http://weather.uwyo.edu.

\subsection{One eruption scenario probability maps associated with strong short-lived plumes (category 1)}

The eruption of 5 January 1990 was the largest explosive event of the last $300 \mathrm{yr}$ (category 1). It began at 03:00 UTC from the southeast crater and lasted for about $35 \mathrm{~min}$ (Calvari et al., 1991; Carveni et al., 1994). Unfortunately, there were few direct observations due to adverse atmospheric conditions, but some samples were collected a few days after the event (Calvari et al., 1991). The pyroclastic deposit covered almost the whole of the WNW Etna flank. The proximal deposit was made up of light spatter bombs and lapilli having a clast density of $1160 \mathrm{~kg} \mathrm{~m}^{-3} .4 \mathrm{~m}$ - and $9 \mathrm{~cm}$ - thick deposits were found at 0.5 and $6.5 \mathrm{~km}$ downwind from the volcanic vent respectively (Calvari et al., 1991). Given that more physical parameters are required to run TEPHRA, some of the collected samples were used to better characterize the eruption. The total erupted mass $M$ and the total grain-size distribution TGSD were estimated by comparing simulations carried out through model validation based on the $m f$ function (Eq. 4). We varied $M$ and TGSD parameters between $1-4 \times 10^{10} \mathrm{~kg}$ and -3 and $2.5 \varphi$, respectively and found, as the best descriptors, $M=1.5 \times 10^{10} \mathrm{~kg}$, in agreement with the value found by Carveni et al. (1994), and $M d_{\varphi}=-0.5 \varphi$. Figure 8 shows the comparison between the grain-size distribution collected near Bronte $(15 \mathrm{~km}$ far from the volcanic vent) and the grain-size computed at the same location by varying the $M d_{\varphi}$ of TGSD between -3 and $2.5 \varphi$. Good agreement is shown for TGSD equal to $-0.5 \varphi$. Direct observations of the column height were not available and a value of $15 \mathrm{~km}$ was derived from the mass eruption rate based on the approach of Sparks et al. (1997).

OES-SSL1 probability maps were hence compiled. In particular, we found that tephra accumulation $\geq 300$ and $\geq 200 \mathrm{~kg} \mathrm{~m}^{-2}$ affects only the region within 5 and $10 \mathrm{~km}$ of the vent respectively, where no towns are present. By contrast, tephra accumulation $\geq 100 \mathrm{~kg} \mathrm{~m}^{-2}$ affects densely
BRONTE

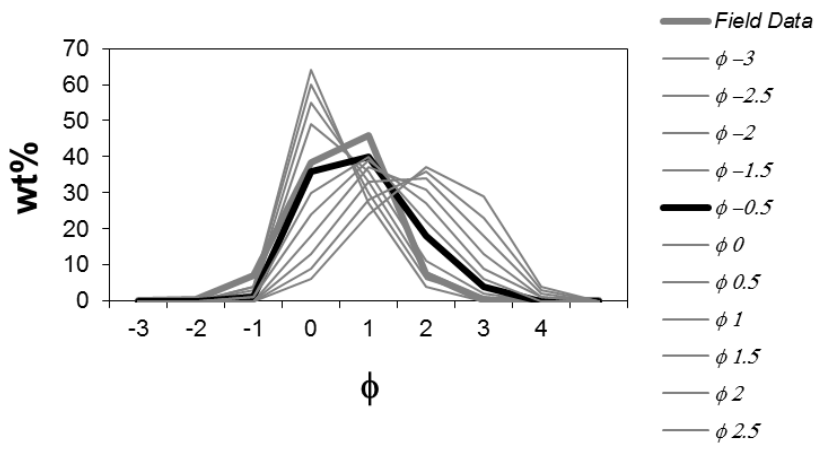

Fig. 8. Comparison between the grain-size distribution collected at Bronte (about $15 \mathrm{~km}$ from the vent) and computed by TEPHRA at the same locality. The $M d_{\varphi}$ of the TGSD used in the simulations varied between -3 and $2.5 \varphi$. The best agreement was obtained for $M d_{\varphi}$ of $-0.5 \varphi$.

populated areas such as Zafferana, although with a low probability (Fig. 9a). Finally, an OES-SSL1 scenario can cause severe damage to agriculture $\left(\geq 10 \mathrm{~kg} \mathrm{~m}^{-2}\right)$ on the eastern flanks of the volcano, having the largest probability of exceeding the hazardous threshold for vegetation (Fig. 9b).

\subsection{One eruption scenario probability maps associated with strong short-lived plumes (category 2)}

The Plinian eruption that occurred in $122 \mathrm{BC}$ was studied in detail by Coltelli et al. (1998), who identified seven pyroclastic units in the stratigraphic succession. The first magmatic phase of the eruption was characterized by the emplacement of widespread coarse-ash fallout (Unit A), small phreatomagmatic deposit (Unit B) and two Plinian fallout deposits (units $\mathrm{C}$ and $\mathrm{E}$ ), separated by a phreatomagmatic episode (Unit D). The eruption ended with a complex phreatomagmatic phase (Unit F) and a post-eruption phreatic activity inside the caldera (Unit G). A $16 \mathrm{~cm}$-thick tephra deposit was collected in a drill core at $5 \mathrm{~km}$ offshore from the Catania coastline and a 1-3 cm-thick tephra deposit was found in the Ionian sea at $400 \mathrm{~km}$ from the vents. During the Plinian phase (units $\mathrm{C}$ and E) a total mass of about $2.8 \times 10^{11} \mathrm{~kg}$ was erupted, and the column height reached 24-26 km a.s.l. (Coltelli et al., 1998). The total grain-size distribution was supposed to be similar to the eruption used for the calibration (1998 Etna eruption) and was fixed at $2.3 \varphi$. Conditional probability maps for this event show that the tephra accumulation has a very high probability (between 50 and $100 \%$ ) of exceeding $100 \mathrm{~kg} \mathrm{~m}^{-2}$ up to about $30 \mathrm{~km}$ from the volcanic vent (Fig. 10). There is also a $20 \%$ probability of exceeding $300 \mathrm{~kg} \mathrm{~m}^{-2}$ within $15 \mathrm{~km}$ of the volcanic vent. Roof collapses may occur in large densely populated areas such as Giarre and Zafferana (between $40 \%$ and $70 \%$ for 300 and $100 \mathrm{~kg} \mathrm{~m}^{-2}$, respectively). 

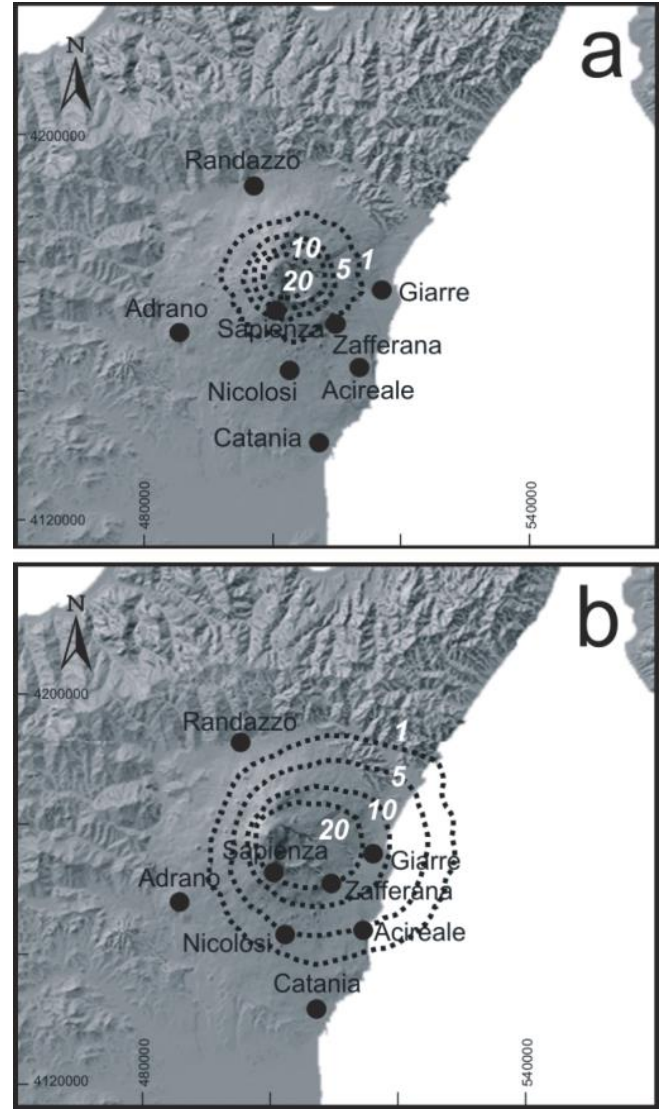

Fig. 9. Probability maps for the OES-SSL1, having similar features to the 5 January 1990 eruption, considering thresholds of (a) $100 \mathrm{~kg} \mathrm{~m}^{-2}$ and (b) $10 \mathrm{~kg} \mathrm{~m}^{-2}$.

\subsection{One eruption scenario probability maps associated with weak long-lived plumes}

The eruption of 2002-2003 began on 26 October 2002 with the opening of a complex system of eruptive fissures on the northeastern (from 3010 to $2920 \mathrm{~m}$ and from 2500 to $1890 \mathrm{~m}$ ) and southern (from 2850 to $2600 \mathrm{~m}$ ) flanks. The eruption ended on 28 January 2003, after three months of almost continuous explosive activity and lava flow emission. Eruption columns up to $7 \mathrm{~km}$ a.s.l. were emitted from the southern fissure continuously for 56 days. Abundant tephra fell on all the volcano's flanks, often forcing the closure of the airports in Catania and Reggio Calabria (Andronico et al., 2005). Lapilli and ash mainly covered the eastern sectors of the volcano due to dominant winds that blew eastward. A total volume of $4.4 \pm 0.6 \times 10^{10} \mathrm{~kg}$ and a total grain-size distribution peaked at $0.5 \varphi$ were estimated by Andronico et al. (2008). Over the past three centuries, this activity has been considered comparable only with the 1763 eruption (Andronico et al., 2005) that was produced from La Montagnola volcanic cone located near the 2002-2003 vent and lasting 84 days (Recupero, 1815).
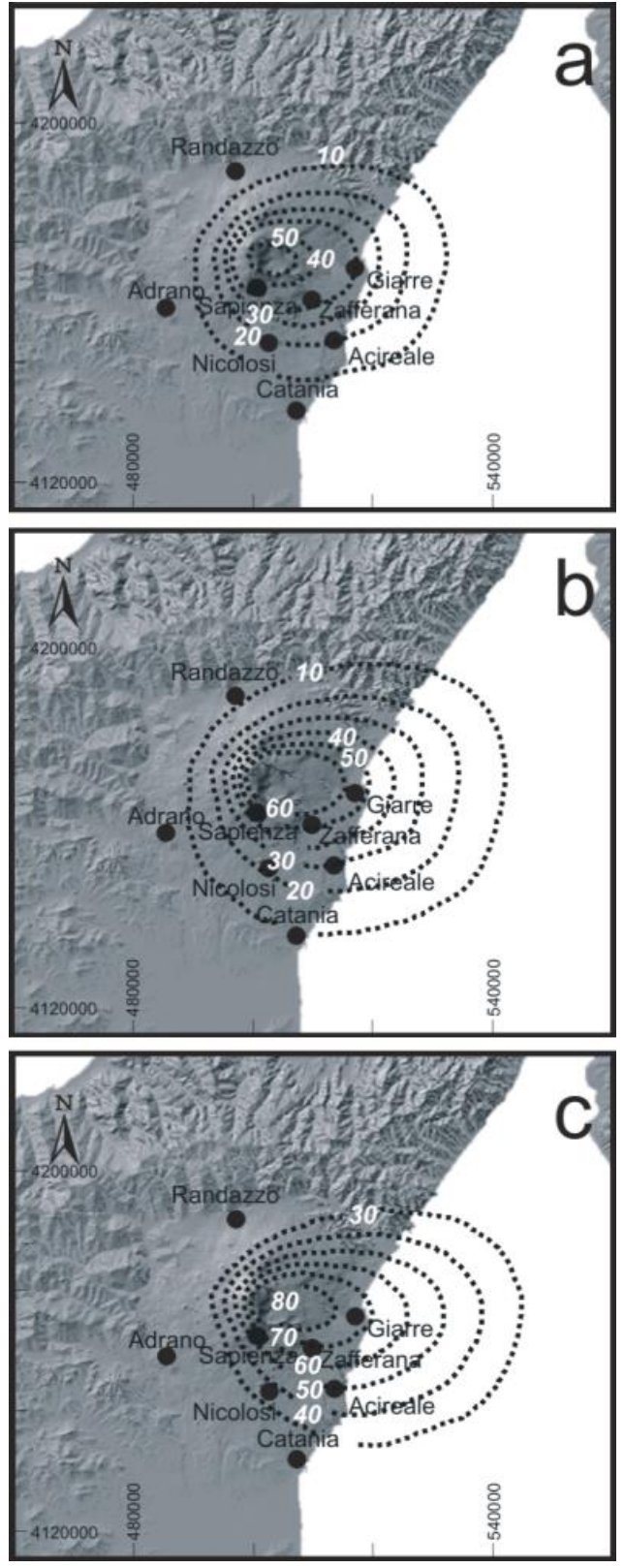

Fig. 10. Probability maps for the OES-SSL2, having similar features to the $122 \mathrm{BC}$ Plinian eruption, considering thresholds of (a) $300 \mathrm{~kg} \mathrm{~m}^{-2}$, (b) $200 \mathrm{~kg} \mathrm{~m}^{-2}$, and (c) $100 \mathrm{~kg} \mathrm{~m}^{-2}$.

The OES-WLL probability maps were compiled considering an eruption lasting 100 days and producing a weak plume of $7 \mathrm{~km}$ a.s.l. Tephra accumulation has a very high probability (between $80-100 \%$ ) of exceeding 200 and $100 \mathrm{~kg} \mathrm{~m}^{-2}$ within 12 and $18 \mathrm{~km}$ of the vent respectively, and mainly affected the southeastern flanks of the volcano (Fig. 11). 

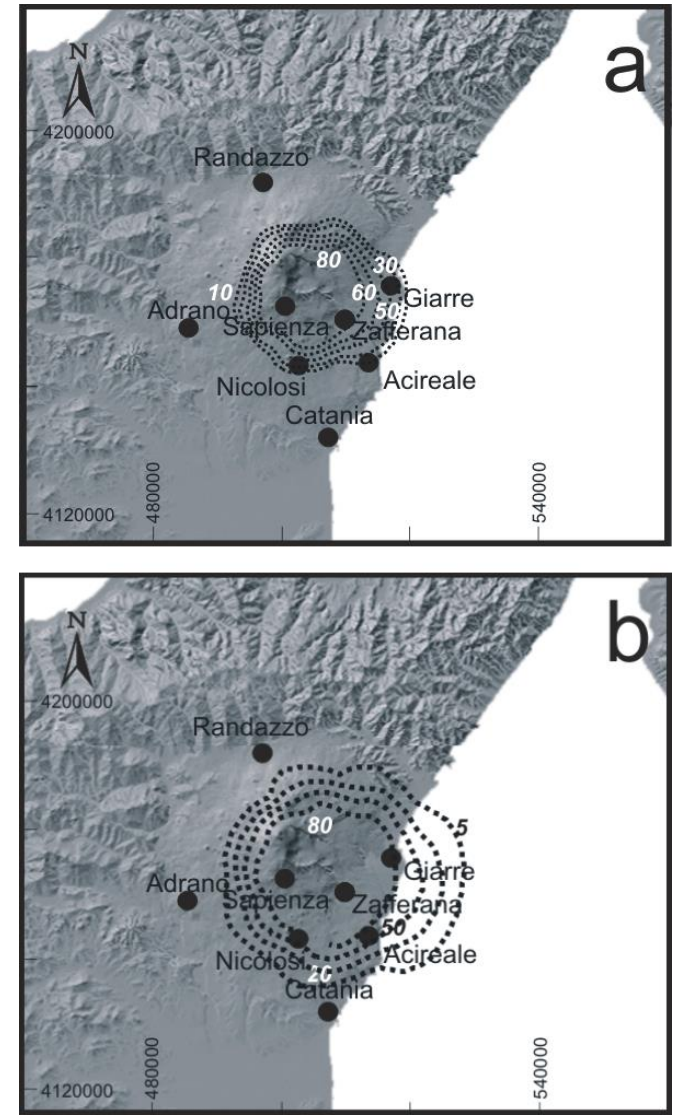

Fig. 11. Probability maps for the OES-WLL, with similar features to the 2002-2003 eruption. Thresholds considered are: (a) 200 and (b) $100 \mathrm{~kg} \mathrm{~m}^{-2}$.

\subsection{Eruption range scenario probability maps associated with weak long-lived plumes}

Eruption range scenario was evaluated for WLL eruptions because only for this case may we consider future prolonged multi-vent activity. From the analysis carried out by Branca and Del Carlo (2005), we consider the column height variable between $3.6 \mathrm{~km}$ and $7 \mathrm{~km}$ a.s.l. (Fig. 12) and the total mass between $1.5 \times 10^{6}$ and $5 \times 10^{9} \mathrm{~kg}$. The duration of the eruption was assumed to be between 4 (2001 Etna eruption) and 100 days (Fig. 13). Both parameters were sampled from a logarithmic distribution according to Bonadonna et al. (2005b) (Table 1). The location of eruptive vents (latitude, longitude and height) was also sampled statistically (Fig. 14a). Probability maps are shown in Fig. 14b, c and d. There is a small probability (between 1 and $20 \%$ ) that the mass loading exceeds $300 \mathrm{~kg} \mathrm{~m}^{-2}$ beyond $15 \mathrm{~km}$, and a slightly higher probability (between 10 and $20 \%$ ) between 10 and $15 \mathrm{~km}$. The probability of exceeding $200 \mathrm{~kg} \mathrm{~m}^{-2}$ is between 1 and $30 \%$ within $20 \mathrm{~km}$. Finally, the probability of exceeding $100 \mathrm{~kg} \mathrm{~m}^{-2}$ is $>20 \%$ at distances $<20 \mathrm{~km}$.

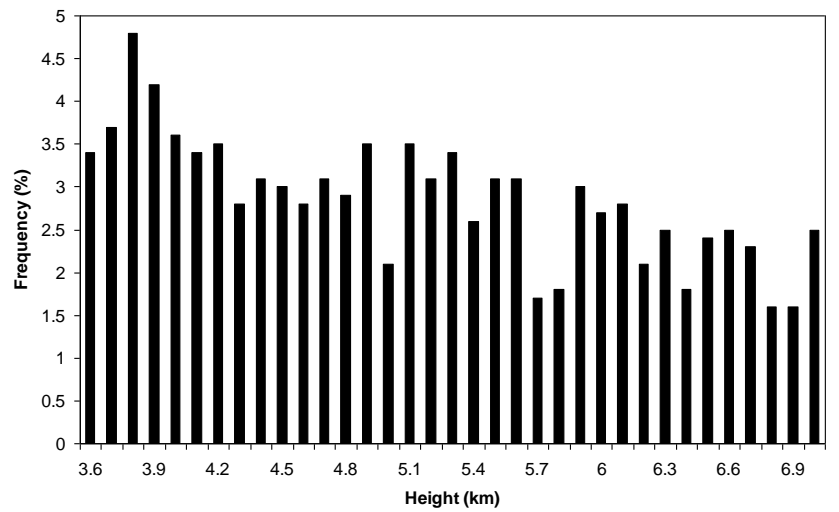

Fig. 12. Column height sampled for the eruption range scenario of long-lived eruptions (ERS-WLL).

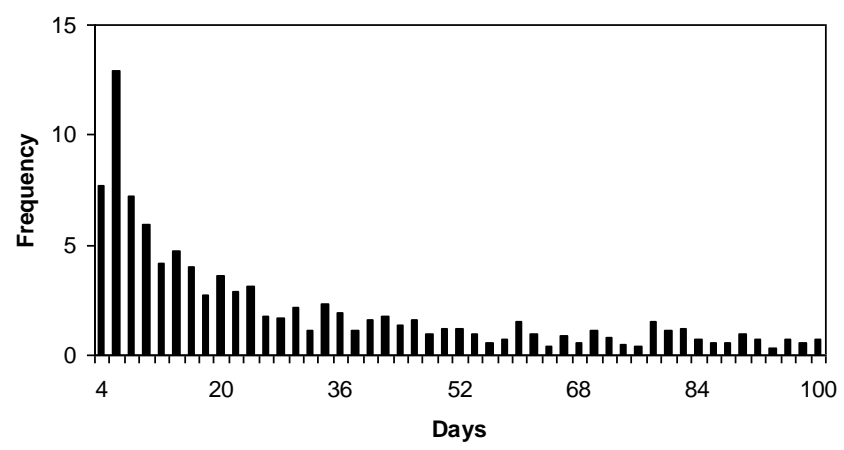

Fig. 13. Eruption duration (days) sampled for the eruption range scenario of long-lived eruptions (ERS-WLL).

\section{Discussion}

The evaluation of eruption source parameters is necessary to reliably model volcanic ash transport during an eruption (Mastin et al., 2009) and to calibrate and validate volcanic ash transport and dispersion models (Scollo et al., 2008a; Bonadonna, 2006). This is why the IAVCEI Commission on Tephra Hazard Modelling compiled a comprehensive data set in order to improve model accuracy by comparisons among data and model results (http://dbstr.ct.ingv.it/iavcei). While detailed field observations are necessary for characterizing explosive activity, numerical models represent a powerful tool to quantitatively analyse the effects caused by eruptions. Over the last $30 \mathrm{yr}$, increasingly sophisticated models have greatly helped to represent the natural system realistically (Sheridan, 1994; Costa and Macedonio, 2005; Ongaro et al., 2012). To evaluate the impact from tephra fallout, the last generation of models (e.g. Bonadonna et al., 2005a; Connor and Connor, 2006; Folch et al., 2008) takes full advantage of parallel programming (Wilkinson and Allen, 1999). 

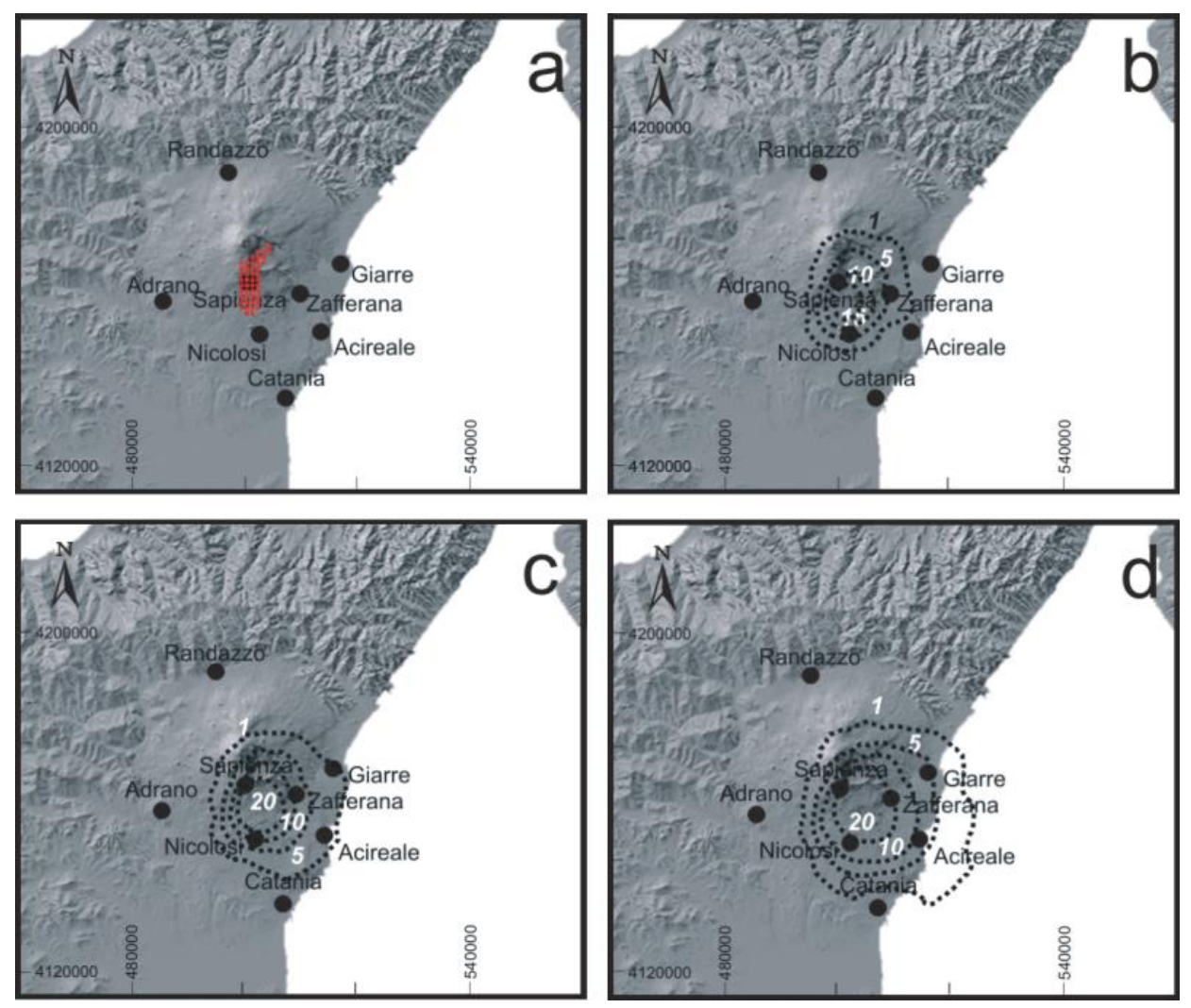

Fig. 14. (a) Location of volcanic vents sampled statistically for the ERS-WLL simulations. Probability maps associated with the ERS-WLL using the thresholds: (b) 300, (c) 200 and (d) $100 \mathrm{~kg} \mathrm{~m}^{-2}$.

Semi-analytical models, such as TEPHRA, are based on the assumption that the total mass is released instantly. As a result, these models cannot typically capture the variation of wind velocity and direction with time and have mostly been used for the hazard assessment of strong and relatively short-lived eruptions. However, our implementation of the TEPHRA model to account for sequential discrete explosive events has also allowed for the compilation of probability maps for long-lived eruptions (WLL), and consequently our results may be compared with those obtained by other models that instead consider the time variability of the eruption, such as FALL3D (Costa et al., 2006) and VOLCALPUFF (Barsotti et al., 2008). The results of the hazard assessment at Etna have indicated that deposits associated with OESWLL eruptions have the highest impact. Probability maps show that mass accumulation $\geq 200$ and $\geq 100 \mathrm{~kg} \mathrm{~m}^{-2}$ can be reached within 18 and $23 \mathrm{~km}$ of the vent. Densely populated cities, located in the eastern flank of the volcano, such as Acireale and Giarre, can then be seriously affected. This is in agreement with the results obtained by Barsotti et al. (2010), who showed that towns and infrastructures on the eastern side of the volcano are significantly more exposed to ash hazard. For these towns the cleanup of roofs and roads is hence required to prevent significant disruption. We found that OES-WLL eruptions could also affect the populated areas of Catania even if the probability of reaching a threshold of $100 \mathrm{~kg} \mathrm{~m}^{-2}$ is relatively low (between 10 and $30 \%$ ). The effect on populated areas (i.e. accumulation of $100 \mathrm{~kg} \mathrm{~m}^{-2}$ ) associated with a larger range of source parameters for WLL (i.e. ERS-WLL) results in lower probabilities, but is not negligeable. In addition, the impact on infratstructures and agriculture associated with Etna eruptions was evaluated for the first time for events similar to the 5 January 1990 event (i.e. the most explosive event of the last $300 \mathrm{yr}$ ) and the $122 \mathrm{BC}$ Plinian eruption. In the case of an exceptional event such as a basaltic Plinian eruption (OES-SSL2 scenario), there is a very high probability that roof collapses may happen within $50 \mathrm{~km}$ of the vent.

Caveats. It should be noted that, for SSL eruptions, TEPHRA does not reproduce the deposit well within the plume corner. The greatest differences between the model and the field data are in fact located between 1.8 and $3.8 \mathrm{~km}$ from the vent. There are also differences for low mass loading $\left(<1 \mathrm{~kg} \mathrm{~m}^{-2}\right)$, for which TEPHRA gives higher values than those observed in the distal region. This could depend on the fact that very thin deposits might not be preserved in distal regions (Bonadonna et al., 2002; Scollo et al., 2007), but it could also reflect the complex dynamics of the long-lasting 
activity. In addition, the absence of topography in the model could generate large uncertainties in the simulated mass loading for column heights of 3-4 km (Scollo et al., 2008b). Nevertheless, the comparison between computed and observed data for the eruptions generating strong short-lived and and weak long-lived plumes used in the calibration is still good (within $50 \%$ ). Consequently, we can conclude that TEPHRA may also provide reliable hazard assessments for this type of eruption, but uncertainties have to be considered during the analysis and interpretation of the resulting probability maps (i.e. $\pm 50 \%$ ). Moreover, $K$ partially depends on the meteorological conditions of specific eruptions that may be different from the meteorological conditions of eruptions considered during calibration. However, in TEPHRA, $K$ accounts for both atmospheric diffusion and gravitational spreading, and the populated areas analysed in our hazard assessment are all located near the active vent, where the contribution of the gravitational spreading dominates.

Finally, particle aggregation is not considered in our simulations, and, therefore, mass loading in proximal areas might be underestimated for fine-rich TGSD. In fact, many tephra deposits could only be reproduced when particle aggregation was described (e.g. Cornell et al., 1983; Bonadonna et al., 2002; Carey and Sigurdsson 1982; Folch et al., 2010), and a certain degree of aggregation was also observed at Etna (Scollo et al., 2005, 2007). However, fine-poor TGSD are not significantly affected by particle aggregation (e.g. Bonadonna and Phillips, 2003), and, consequently, we do not expect the OES-SSL1, OES-WLL and ERS-WLS to be significantly affected (Table 1).

\section{Concluding remarks}

In this work, a detailed hazard assessment was carried out on the basis of two different typologies of Etna eruptions: eruptions associated with strong short-lived plumes (SSL eruptions) and eruptions associated with weak long-lived plumes (WLL eruptions). Four different scenarios and long-lived multi-event activity were considered in order to describe the large variability that may occur at basaltic volcanoes such as Etna. Results clearly show that the eastern flank could be strongly affected by all explosive activities due to the prevailing wind direction. In particular, eruptions such as the 2002-2003 lasting 100 days and 122 BC Plinian eruptions, the latter never considered before, are the most dangerous, with the highest probability of roof collapse. However, severe damages to agriculture may occur on the eastern side of volcano for all the different eruption types considered in our study. For more comprehensive hazard assessment and better quantification of uncertainties, future research could include additional eruptive scenarios such as the recent lava fountaining activities in 2011, 2012 and 2013, as well as different volcanic ash dispersal models.
Acknowledgements. The authors are grateful to the Istituto Nazionale di Geofisica e Vulcanologia and to the University of Hawaii for supporting this project. We are also grateful to L. Connor for her advice on the TEPHRA implementation carried out in this work, to F. Rapicavoli for the help given during the analysis of wind data, D. Andronico for allowing us to use field data collected during the 1998 Etna eruption, and G. Spata. We also thank A. Folch, M. Pistolesi and A. Costa for their constructive and very helpful reviews. This work was supported by an INGV-GNV fellowship, the "Sviluppo Nuove Tecnologie per la Protezione e Difesa del Territorio dai Rischi Naturali" MIUR-FIRB Italian project and civil protection department for one of the authors (S. Scollo). Stephen Conwey is sincerely thanked for the help with the compilation of the English text.

Edited by: A. Costa

Reviewed by: M. Pistolesi, A. Folch, and one anonymous referee

\section{References}

Aloisi, M., D’Agostino, M., Dean, K., G., Mostaccio, A., and Neri, G.: Satellite analysis and PUFF simulation of the eruptive cloud generated by the Mount Etna paroxysm of 22 July 1998, J. Geophys. Res., 107, 2373, doi:10.1029/2001JB000630, 2002.

Alparone, S., Andronico, D., Sgroi, T., Ferrari, F., Lodato, L., and Reitano, D.: Alert system to mitigate tephra fallout hazards at Mt. Etna Volcano, Italy, Nat. Hazards, 43, 333-350, 2007.

Andronico, D., Del Carlo, P., and Coltelli, M.: The 22 July 1998 fire fountain episode at Voragine Crater (Mt Etna, Italy), Volcanic and Magmatic Studies Group, Annual Meeting, 5-6 January 1999, Birmingham, 1999.

Andronico, D., Branca, S., Calvari, S., Burton, M. R., Caltabiano, T., Corsaro, R. A., Del Carlo, P., Garfì, G., Lodato, L., Miraglia, L., Murè, F., Neri, M., Pecora, E., Pompilio, M., Salerno, G., and Spampinato, L.: A multi-disciplinary study of the 2002-03 Etna eruption: Insights for a complex plumbing system, Bull. Volcanol., 67, 314-330, 2005.

Andronico, D., Scollo, S., Cristaldi A., and Caruso, S.: The 2002-03 Etna explosive activity: tephra dispersal and features of the deposit, J. Geophys. Res., 113, B04209, doi:10.1029/2007JB005126, 2008.

Andronico, D., Scollo, S., Cristaldi, A., and Ferrari, F.: Monitoring the ash emission episodes at Mt. Etna: the 16 November 2006 case study, J. Volcanol. Geotherm. Res., 180, 123-134, 2009.

Armienti, P., Macedonio, G., and Pareschi, M. T.: A numericalmodel for simulation of tephra transport and depositionapplications to May 18 1980, Mount St-Helens eruption, J. Volcanol. Geotherm. Res., 93, 6463-6476, 1988.

Barberi, F., Macedonio, G., Pareschi, M. T., and Santacroce, R.: Mapping the tephra fallout risk: an example from Vesuvius, Italy, Nature, 344, 142-144, 1990.

Barnard, S. T.: Results of a reconnaissance trip to Mt. Etna, Italy: The effects of the 2002 eruption of Etna on the province of Catania, Bull. New Zealand Soc. Earthquake Eng., 37, 47-62, 2004.

Barsotti, S., Neri, A., and Scire, J. S.: The Vol-CALPUFF model for atmospheric ash dispersal: I Approach and physical formulation, J. Geophys. Res., 113, B03208, doi:10.1029/2006JB004623, 2008. 
Barsotti, S., Andronico, D., Neri, A., Del Carlo, P., Baxter, P. J., Aspinall, W. P., and Hincks, T.: Quantitative assessment of volcanic ash hazards for health and infrastructure at Mt. Etna (Italy) by numerical simulation, J. Volcanol. Geotherm. Res., 192, 85-96, 2010.

Blong, R. J.: Volcanic Hazards. A sourcebook on the effects of eruptions. Academic Press, Sidney, 1984.

Bonadonna, C.: Probabilistic modelling of tephra dispersal, in: Statistics in Volcanology, edited by: Mader, H., Cole, S., and Connor, C. B., IAVCEI Series, Volume 1, Geological Society of London, 2006.

Bonadonna, C. and Costa, A.: Modeling of tephra sedimentation from volcanic plumes, in: Modeling Volcanic Processes: The Physics and Mathematics of Volcanism, Cambridge University Press, edited by: Fagents, S. A., Gregg, T. K. P., and Lopes, R. M. C., ISBN: 9780521895439, 2013.

Bonadonna, C. and Houghton, B. F.: Total grain-size distribution and volume of tephra-fallout deposits, Bull. Volcanol., 67, 441456, 2005

Bonadonna, C. and Phillips, J. C.: Sedimentation from strong volcanic plumes, J. Geophys. Res., 108, 2340, doi:10.1029/2002JB002034, 2003.

Bonadonna, C., Ernst, G. G. J., and Sparks, R. S. J.: Thickness variations and volume estimates of tepha fall deposits: the importance of particle Reynolds number, J. Volcanol. Geotherm. Res., 81, 173-187, 1998.

Bonadonna, C., Macedonio, G., and Sparks, R. S. J.: Numerical modelling of tephra fallout associated with dome collapses and Vulcanian explosions: application to hazard assessment on Montserrat, Geological Society, London, Memoir, 2002.

Bonadonna, C., Connor, C. B., Houghton, B. F., Sahetapy-Engel, S., Hincks, T., and Connor, L.: Probabilistic modelling of tephra dispersion: Hazard assessment of a multi-phase rhyolitic eruption at Tarawera, New Zealand, J. Geophys. Res., 110, B03203, doi:10.1029/2003JB002896, 2005a.

Bonadonna, C., Phillips, J. C., and Houghton, B. F.: Modelling tephra sedimentation from a Ruapeho weak plume eruption, J. Geophys. Res., 110, B08209, doi:10.1029/2004JB003515, $2005 b$.

Branca, S. and Del Carlo, P.: Types of eruptions of Etna Volcano AD 1670-2003: Implications for short-term eruptive behaviour, Bull. Volcanol., 67, 732-742, 2005.

Bursik, M. I., Carey, S. N., and Sparks, R. S. J.: A gravity current model for the May 18, 1980 Mount-St-Helens plume, Geophys. Res. Lett., 19, 1663-1666, 1992.

Calvari, S., Coltelli, M., Pompilio, M., and Scrivano, V.: The eruptive activity between October 1989 and December 1990, Acta Vulcanol., 1, 257-260, 1991.

Carey, S. N. and Sparks, R. S. J.: Quantitative models of the fallout and dispersal of tephra from volcanic eruption columns, Bull. Volcanol., 48, 109-125, 1986.

Carveni, P., Romano, R., Caltabiano, T., Grasso, M. F., and Gresta, S.: The exceptional esplosive activity of 5 January 1990 at SECrater of Mt Etna volcano (Sicily), Boll. Soc. Geol. It., 113, 613631, 1994

Casadevall, T. J.: Volcanic Ash and Aviation Safety: Proceedings of the First International Symposium on Volcanic Ash and Aviation Safety, US Geological Survey Bulletin, vol. 2047, 1994.
Cioni, R., Longo, A. Macedonio, G., Santacroce, R., Sbrana, A., Sulpizio, R., and Andronico, D.: Assessing pyroclastic fall hazard through field data and numerical simulations: Example from Vesuvio, J. Geophys. Res., 108, 2063 , doi:10.1029/2001JB000642, 2003.

Coltelli, M., Del Carlo, P., and Vezzoli, L.: The discovery of a Plinian basaltic eruption of Roman age at Mt. Etna, Geology, 26, 1095-1098, 1998.

Connor, L. G. and Connor, C. B.: Inversion is the key to dispersion: Understanding eruption dynamics by inverting tephra fallout, in: Statistics in Volcanology, Society for Industrial and Applied Mathematics, Special Publication of IAVCEI No. 1, edited by: Mader, H., Cole, S., and Connor, C. B., 231-242, Geological Society, London, 2006.

Connor, C. B., Hill, B. E., Winfrey, B., Franklin, N. M., and La Femina, P. C.: Estimation of volcanic hazards from tephra fallout, Nat. Hazards Rev., 2, 33-42, 2001.

Cornell, W., Carey, S., and Sigurdsson, H.: Computer-simulation of transport and deposition of the Campanian Y-5 ash, J. Volcanol. Geotherm. Res., 17, 89-109, 1986.

Costa, A. and Macedonio, G.: Numerical simulation of lava flows based on depth-averaged equations, Geophys. Res. Lett., 32, 1-5, doi:10.1029/2004GL021817, 2005.

Costa, A., Macedonio, G., and Folch, A.: A three dimensional Eulerian model for transport and deposition of volcanic ashes, Earth Planet. Sci.Lett., 241, 634-647, 2006.

Del Carlo, P., Vezzoli, L., and Coltelli, M.: Last 100 ka tephrostratigraphic record of Mount Etna, in: Mt. Etna: Volcano Laboratory, edited by: Bonaccorso, A., Calvari, S., Coltelli, M., Del Negro C., and Falsaperla, S., AGU Geophysical Monograph Series, 2004.

Ernst, G. G. J., Sparks, R. S. J., Carey, S. N., and Bursik, M. I.: Sedimentation from turbulent jets and plumes, J. Geophys. Res. 101, 5575-5589, 1996.

Eychenne, J. and Le Pennec, J. L.: Sigmoidal particle density distribution in a subplinian scoria fall deposit, Bull. Volcanol., 74, 2243-2249, 2012.

Folch, A., Cavazzoni, C., Costa, A., and Macedonio, G.: An automatic procedure to forecast tephra fallout, J. Volcanol. Geotherm. Res., 177, 767-777, 2008.

Folch, A., Costa, A., Durant, A., and Macedonio, G.: A Model for Wet Aggregation of Ash Particles in Volcanic Plumes and Clouds: II. Model Application, J. Geophys. Res., 115, B09202, doi:10.1029/2009JB007176, 2010.

Horwell, C. J. and Baxter, P. J.: The respiratory health hazards of volcanic ash: a review for volcanic risk mitigation, Bull. Volcanol., 69, 1-24, 2006.

Houghton, B. F. and Wilson, C. J. N.: A vesicularity index for pyroclastic deposits, Bull. Volcanol., 51, 451-462, 1989.

Hurst, A. W. and Turner, R.: Performance of the mass program ASHFALL for forecasting ashfall during the 1995 and 1996 eruptions of Ruapehu Volcano, N. Z. J. Geol. Geophys., 42, 615622, 1999.

Hurst, T. and Smith, W.: A Monte Carlo methodology for modeling ashfall hazards, J. Volcanol. Geotherm. Res., 138, 393-403, 2004.

Macedonio, G., Costa, A., and Longo, V.: A computer model forvolcanic ash fallout and assessment of subsequent hazard, Comput. Geosci., 31, 837-845, 2005. 
Magill, C. R., Hurst, A. W., Hunter, L. J., and Blong, R. J.: Probabilistic tephra fall simulation for the Auckland region, New Zealand, J. Volcanol. Geotherm. Res., 153, 370-386, 2006.

Mannen, K: Total grain size distribution of a mafic subplinian tephra, TB-2, from the 1986 Izu-Oshima eruption, Japan: an estimation based on a theoretical model of tephra dispersal, J. Volcanol. Geotherm. Res., 155, 1-17, 2006.

Mastin, L. G., Guffanti, M., Servranckx, R., Webley, P., Barsotti, S., Dean, K., Durant, A., Ewert, J. W., Neri, A., Rose, W. I., Schneider, D., Siebert, L., Stunder, B., Swanson, G., Tupper, A., Volentik, A., and Waythomas, C. F.: A multidisciplinary effort to assign realistic source parameters to models of volcanic ash-cloud transport and dispersion during eruptions, J. Volcanol. Geotherm. Res., 186, 10-21, 2009.

Miller, T. P. and Casadevall, T. J.: Volcanic Ash Hazards to Aviation, Encyclopedia of Volcanoes, edited by: Sigurdsson, H., Academic Press, San Diego, CA, 2000.

Morton, B., Taylor, G. L., and Turner, J. S.: Turbulent gravitational convection from maintained and instantaneous source, Proc. Roy. Soc., 234, 1-23, 1956.

Ongaro, T. E., Clarke, A. B., Voight, B., Neri, A., and Widiwijayanti, C.: Multiphase flow dynamics of pyroclastic density currents during the May 18, 1980 lateral blast of Mount St. Helens, J. Geophys. Res., 117, 1-22, doi:10.1029/2011JB00908, 2012.

Prata, A. J. and Grant, I. F.: Retrieval of microphysical and morphological properties of volcanic ash plumes from satellite data: Application to Mt Ruapehu, New Zealand, Q. J. R. Meteorol. Soc., 127, 2153-2180, 2001.

Recupero, G.: Storia naturale e generale dell'Etna. Dafni, Tringali Editore, Catania, 1970, 1815.

Rittmann, A.: Structure and evolution of Mount Etna. Philos. Trans. R. Soc. London, 274, 5-16, 1973.

Scollo, S., Coltelli, M., Prodi, F., Folegani, S., and Natali, S.: Terminal settling velocity measurements of volcanic ash during the 2002-2003 Etna eruption by an X-band microwave rain gauge disdrometer, Geophys. Res. Lett., 32, L10302, doi:10.1029/2004GL022100, 2005.
Scollo, S., Del Carlo, P., and Coltelli, M.: Tephra fallout of 2001 Etna flank eruption: Analysis of the deposit and plume dispersion, J. Volcanol. Geotherm. Res., 160, 147-164, 2007.

Scollo, S., Tarantola, S., Bonadonna, C., Coltelli, M., and Saltelli, A.: Sensitivity analysis and uncertainty estimation for tephra dispersal models, J. Geophys. Res., 113, 1-17, doi:10.1029/2006JB004864, 2008a.

Scollo, S., Folch, A., and Costa, A.: A parametric and comparative study of different tephra fallout models, J. Volcanol. Geotherm. Res., 176, 199-211, 2008b.

Scollo, S., Prestifilippo, M., Spata, G., D’Agostino, M., and Coltelli, M.: Monitoring and forecasting Etna volcanic plumes, Nat. Hazards Earth Syst. Sci., 9, 1573-1585, doi:10.5194/nhess-9-15732009, 2009.

Sheridan M. F.: Volcanology - from model to reality, Nature, 367, p. 514, 1994.

Sparks, R. S. J. and Wilson, L.: Explosive volcanic eruptions: V. Observations of plume dynamics during the 1979 Soufrière eruption, St. Vincent, Geophys. J. Roy. Astr. S., 69, 551-570, 1982.

Sparks, R. S. J., Bursik, M. I., Carey, S. N., Gilbert, J. S., Glaze, L. S., Sigurdsson, H., and Woods, A. W.: Volcanic Plumes, John Wiley \& Sons, Chichester, 1997.

Suzuki, T.: A theoretical model for dispersion of tephra. Arc Volcanism, Physics and Tectonics, Terra Scientific Publishing Company Terrapub, Tokyo, 1983.

Tilling, R. I. and Lipman, P. W.: Lessons in reducing volcano risk, Nature, 364, 277-280, 1993.

Wilkinson, B. and Allen, M.: Parallel Programming: Techniques and Applications Using Networked Workstations and Parallel Computers, Prentice-Hall, 1999.

Woods, W.: The dynamics of explosive volcanic eruptions, Rev. Geophys., 33, 495-530, 1995. 